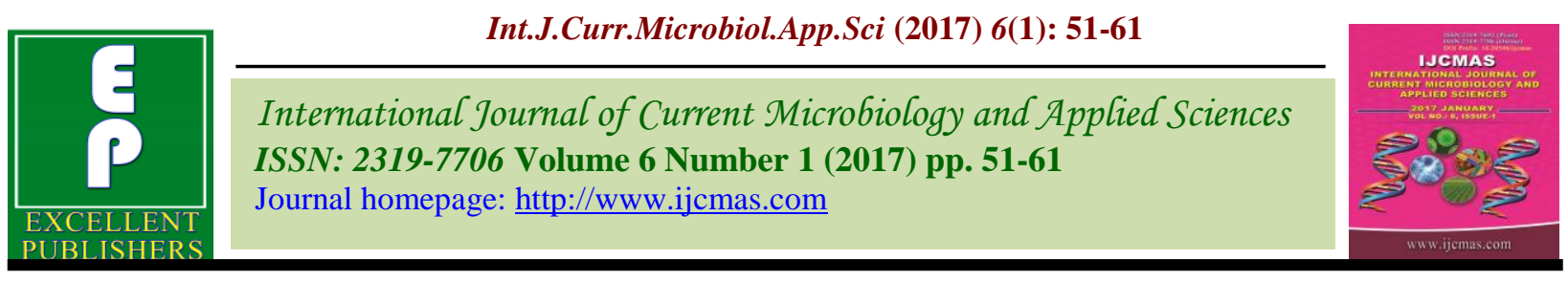

Original Research Article

http://dx.doi.org/10.20546/ijcmas.2017.601.007

\title{
Incidence and Molecular Analysis of Vibrio cholerae among Some Primitive Tribes in Odisha, India
}

\author{
G.P. Chhotray ${ }^{1}$, M.R. Ranjit ${ }^{1}$, B.B. Pal ${ }^{1}$, P.K. Meher $^{2}$ and H.K. Khuntia ${ }^{1} *$ \\ ${ }^{1}$ Regional Medical Research Centre, Chandrasekharpur, Bhubaneswar- 751023, India \\ ${ }^{2}$ Central Institute of Fresh water Aquaculture (CIFA), Kausalya Ganga, \\ Bhubaneswar- 751002, India \\ *Corresponding author
}

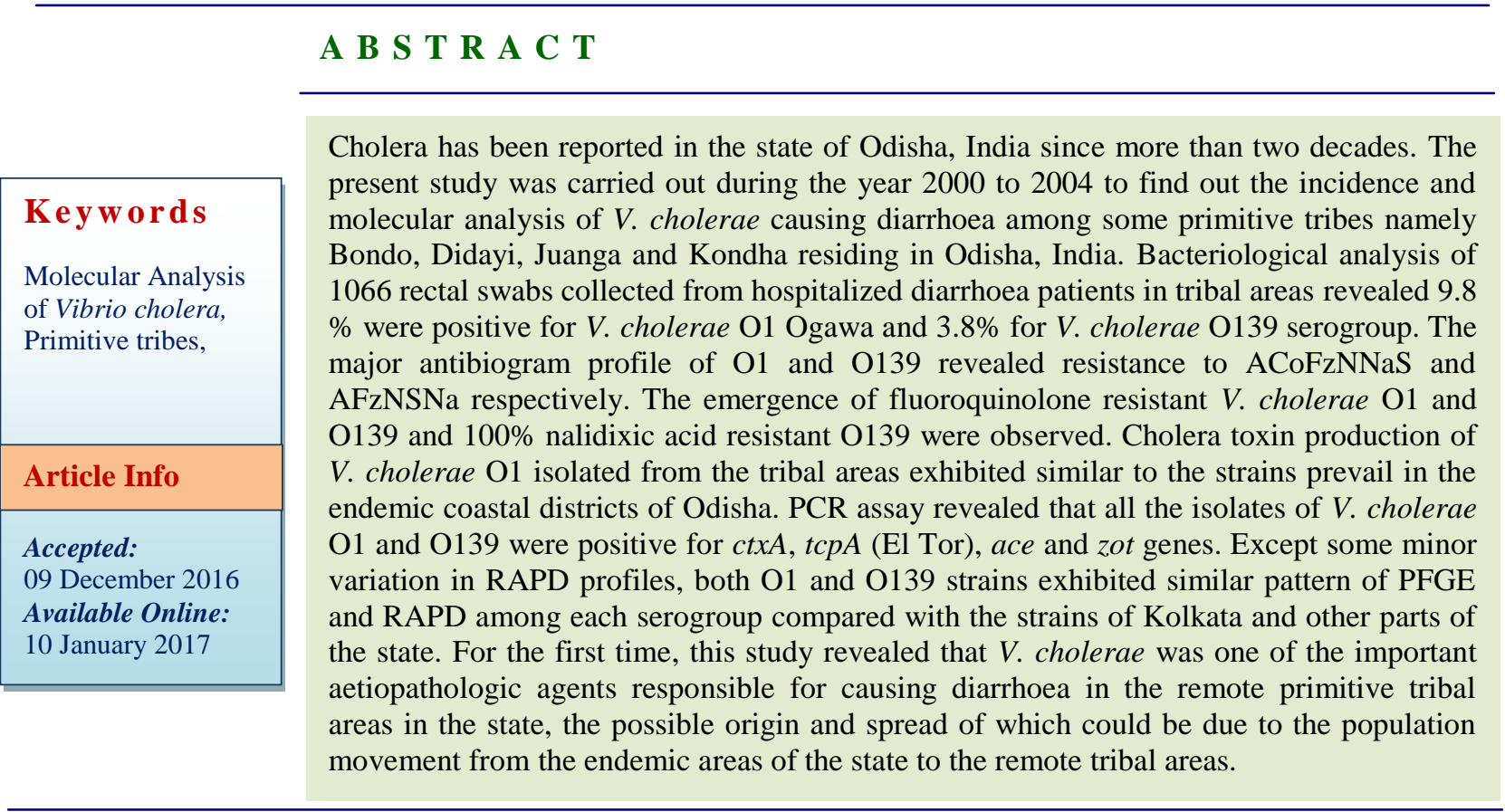

\section{Introduction}

Epidemic and endemic cholera is a major public health problem and continues to be an important cause of morbidity and mortality in developing world. The causative agent $V$. cholerae $\mathrm{O} 1$ and since 1992 V. cholerae $\mathrm{O} 139$ is capable of pandemic spread (Levine et al., 1993). Seven distinct pandemics of cholera have been recorded since 1817 (Kaper et al., 1995).The eighth pandemic was suspected when a new serotype O139 was emerged as an epidemic strain and spread from Chenai to other parts of the country and Bangladesh (Kaper et al., 1995; Ramamurthy et al., 1993). The causative agent of the sixth and perhaps the fifth pandemic belonged to the classical biotype of $V$. cholera (Kaper et al., 1995). The seventh pandemic was caused by $V$. cholera $\mathrm{O} 1 \mathrm{El}$ Tor biotype. After its emergence in the Island of Sulawesi of Indonesia, it spread to Indian subcontinent and reached other countries including Latin America through different routes. Cholera due 
to $V$. cholera $\mathrm{O} 1 \mathrm{El}$ Tor reemerged in Americas in 1991 after 100 years absence in the form of explosive outbreak in Peru and spread rapidly to other South American countries at the rate of one country per month approximately (Tauxe and Blake, 1992). Between 1991 and 1994 more than one million cases affected by cholera were reported in Latin American countries (Koo et al., 1999). The explosive outbreak among Rwandan refugees in Zaire in July 1994 which affected 70,000 people and killed 12000 is another example of its potentiality for rapid spread (Goma, 1994; Sidique et al., 1995) particularly among marginalized or secluded populations. The invasion of cholera in Nichobar island (India) among tribal population in 2002 is another startling event in the history of cholera where $V$. cholerae gained access to this hitherto unaffected population (Sugunan et al., 2004). Cholera has been reported in coastal districts of Odisha, since two decades (Niyogi et al., 1994; Pal et al., 2000; Chhotray et al., 2002; Samal et al., 2001). However its etiology was not reported among primitive tribes living in the hill regions of Northern platue and Eastern Ghats, 500-600 kilometer away from the Bay of Bengal.

Odisha an eastern peninsular state of Indian subcontinent occupies a unique place in the tribal map including primitive 13 tribes. Amongst these 13 primitive tribes, 4 primitive tribes (Bondo, Didayi, Juanga and Kondha) belonging to the Mundari group of Proto-Astroid family are very poor in health status due to their isolation, remoteness, illiteracy, poverty, faulty feeding habits and being largely unaffected by the developmental processes going in the country. Diarrhoeal disorder is one of the major public health problems among primitive tribes with increased morbidity and higher mortality. V.cholerae being one of the important potential etiological agents of diarrhoeal disease, the knowledge of its incidence was still lacked among the primitive tribes in Odisha. This is the first study to report the incidence, origin and spread of $V$. cholerae causing diarrhoea amongst the four primitive tribes.

\section{Materials and Method}

\section{Study population}

A cross sectional study was undertaken from 2000 to 2004 amongst 4 primitive tribes (Bondo, Didayi, Kondha and Juanga) living in four different geographical regions of the state (Fig-1). The study was conducted in four phases in 17 villages from Bondo, 15 from Didayi, 25 from Kondha and 35 from Juanga, which were selected by PPS (population proportion size) sampling procedure. The sample size was calculated taking into account the prevalence rate of diarrhoeal diseases from the government of Odisha, health department (statistics). The study population includes 1012 Bondo, 1009 Didayi, 1298 Kondho and 1137 Juanga tribes. All the diarrhea patients admitted to hospitals of that locality were recruited during the study period. Informed consent was obtained from patients and/or close relatives. The study was reviewed and approved by the ethical committee of Regional Medical Research Center (RMRC) under Indian Council of Medical Research (ICMR).

\section{Bacteriology and Serogroup}

Rectal swabs were collected from freshly admitted cases in the hospitals in tribal areas having acute diarrhoeal symptoms before any treatment was initiated by the government health authorities. Rectal swabs in Cary Blair transport medium (CBT) were transported to the Regional Medical Research Center (RMRC) laboratory for bacteriological analysis to isolate $V$. cholerae 
(Mukhopadhaya et al., 1996; WHO 1987). Diarrhea is defined as three or more watery or loose stools in a 24-hour period prior to admission to the hospital. A multi-test medium was used for presumptive identification of $V$. cholerae (WHO, 1987; Kaper, 1979). All the strains were subsequently subjected for oxidase reaction. Serology was done using slide agglutination with polyvalent and mono-valent antisera specific for Ogawa and Inaba (Difco, USA) and 0139 antisera prepared and supplied by National Institute of cholera and Enteric Diseases (NICED), Kolkata, India. Strains of $V$. cholerae from each serogroup of $\mathrm{O} 1$ and O139 were selected for molecular typing based on antibiograms and geographical locations of tribal and non-tribals for comparison.

\section{Antimicrobial susceptibility}

Antimicrobial sensitivity pattern was tested for isolated $V$. cholerae strains following the Kirby-Bauer technique (16) with the antibiotics (Hi-media Laboratories, Bombay,

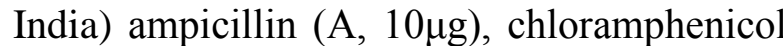

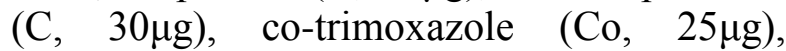
ciprofloxacin (Cf, $5 \mu \mathrm{g}$ ), furazolidone (fz, $100 \mu \mathrm{g})$, gentamicin $(\mathrm{G}, 10 \mu \mathrm{g})$, neomycin $(\mathrm{N}$, $30 \mathrm{~g})$, nalidixic acid $(\mathrm{Na}, 30 \mu \mathrm{g})$, norfloxacin

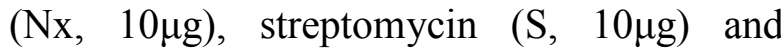
tetracycline $(\mathrm{T}, 30 \mu \mathrm{g})$. Characterization of strains as susceptible, intermediate or resistant was determined based on the size of the inhibition zone around each disc according to manufacturer's instruction. Strains showing an intermediate zone of inhibition were interpreted as resistant to that drug on the basis of previous minimum inhibition of concentration (MIC) studies conducted with V. cholerae (Yamamoto et al., 1995).

\section{Cholera toxin assay}

A monosialoganglioside $\left(\mathrm{GM}_{1}\right)$ enzymelinked immunosorbent assay (ELISA) was used to examine cholera toxin production synthesized by isolated $V$. cholerae $\mathrm{O} 1$ and O139 including two control strains (VC20, El Tor Biotype, O1 and SG24, O139) by the method Svennerholm and Holmgren (Svennerholm and Holmgren, 1978).

\section{Molecular analysis}

\section{Polymerase Chain Reaction (PCR) assay}

The virulence factors of V.cholerae encoding $c t x A$ ( A-sub unit of cholera toxin gene), tcpA (major structural subunit of toxin co-regulated pilus), zot (zonnula occluden toxin) and ace (accessory cholera entero toxin) were detected by PCR technique using specific primers as described elsewhere (Chhotray et al., 2002; Shi et al., 1998). Randomly amplified polymorphic DNA (RAPD) PCR assay was performed selected $V$. cholerae strains with 1281 and 1283 primers to check the clonality as in previous study (Chhotray et al., 2002). The fingerprinting pattern obtained from RAPD (1281) of tribal and coastal strains were compared to ascertain the phylogenetic relationship between the two groups by using Quantity-1 software and dendrogram was generated using SAS (SAS Institute, 1989).

\section{Pulsed Field Gel Electrophoresis (PFGE)}

Genomic DNA of strains of $V$. cholerae was prepared in agarose plugs as described previously by (Sinha et al., 2001) to carryout PFGE. PFGE was performed using the counter clamped homogenous electric field method on a CHEF Mapper system (BioRad, California, USA) with 1\% PFGE grade agarose in $0.5 \mathrm{X}$ TBE buffer for 26 hour. Run conditions were generated by the autoalgorithm mode of CHEF Mapper PFGE system using a size range of $20-300 \mathrm{~kb}$. The gels were stained for 30 min with solution of $20-10 \mu \mathrm{g} / \mathrm{ml}$ ethidium bromide, destained in water for $15 \mathrm{~min}$ and photographed under UV 


\section{Results and Discussion}

A total of 1066 rectal swabs collected from patients with secretory diarrhoea were bacteriologically analyzed during the period under study. Of the total samples $V$. cholerae O1 Ogawa was $9.8 \%$ and V. cholerae $\mathrm{O} 139$ $3.8 \%$ serogroup, Table-1.

The antibiogram profile of strains of $V$. cholerae $\mathrm{O} 1 \& \mathrm{O} 139$ against commonly used antibiotics, revealed interesting shifts in the patterns of resistance during the study period. The dominant drug resistance profile of $V$. cholerae $\mathrm{O} 1$ and $\mathrm{O} 139$ in 2000 and 2001 were ACoFzNNaS and AFzNSNa respectively. The incidence of fluoroquinolone resistant isolates of $\mathrm{O} 1$ \& $\mathrm{O} 139$ was observed in variable proportion. The striking feature is the emergence of complete $(100 \%)$ nalidixic acid resistant strains of $V$. cholerae $\mathrm{O} 139$ for the first time during the study. Thus the results obtained demonstrate that $V$. cholerae $\mathrm{O} 1 \&$ O139 isolated during the study period had high rates of resistant to various antibiotics tested.

All the strains of $V$. cholerae $\mathrm{O} 1 \& \mathrm{O} 139$ were analyzed using specific primers to detect $\operatorname{ctxA}, \operatorname{tcp} A$, and two other genes zot and ace which putatively encode additional toxins. Our results revealed the presence of the core toxin region among the isolates of $\mathrm{O} 1$ and O139 and confirmed the co-occurrence of tcpA (El Tor), ctxA, zot and ace in all $\mathrm{O} 1$ and O139 strains.

RAPD PCR fingerprinting carried out on the five representative isolates from each of the two serogroups generated identical arrays of DNA fragments with one primer, 1283 (Fig 2a, b). Interestingly, the other primer (1281) (Fig3a,b) exhibited a slightly varied RAPD PCR profile for the O1 and O139 strains of Primitive tribes from those of the other part of the state as well as of the country. The relatedness between the genomic DNA fingerprinting obtained from RAPD band profile of the $\mathrm{O} 1$ and $\mathrm{O} 139$ strains of coastal and tribal district were estimated and presented as a dendrogram (Fig 4a, b) using average linkage determined by the CLUSTER and TREE procedure SAS.

PFGE profiles of strains of both the serogroups from the study area and from the other geographical locations of the state is shown in Fig-5. All the 4 strains of O1 Ogawa examined, showed identical banding pattern to that exhibited by $\mathrm{CO} 840$, the new clone of O1, which appeared in Calcutta in 1994. Similarly, the banding pattern of four O139 strains of both tribal and coastal districts matched with that of $\mathrm{O} 139$ reference strain ATCC 51394, the Madras (India) outbreak strain in 1992. Thus, each serogroup of O1 and $\mathrm{O} 139$ of tribal and coastal districts of widely distanced geographical locations exhibited similar PFGE profile as prevailing in other parts of the country

In the present study the outbreak of cholera was reported in 2000 due to $V$. cholerae $\mathrm{O} 1$ and $\mathrm{O} 139$ among the four primitive tribes in different geographical regions, $\mathrm{O} 1$ being the predominant serogroup. All the O1 strains were biotype El Tor, Ogawa, similar to the trend documented in other part of the state as well as in India. Very interestingly although $V$. cholerae $\mathrm{O} 139$ after its emergence in Madras in 1992 was spread to Kolkata in 1992 and Visakhapatanum in 1993 (Nair et al., 1994), its emergence was not reported till Sept 1995 (Pal et al., 2000) in Odisha which is situated midway between these two places. After emergence in 1995 (Pal et al., 2000) and reemergence in June 1999 in coastal district (Unpublished data), O139 gained it's entry to the tribal land during November 2000 for the first time. In the present study the incidence and isolation of cholera was on a 
higher side during the interval of first year of study. There was a gradual decrease in the isolation rate of $V$. cholerae in the second and third year and there was not a single case of cholera reported during fourth year in whole of the study area. This may be due to the institution of effective intervention measures in the form of immediate treatment, health awareness and intense IEC activities or the spread might be temporary at high hilltop region.

The results of antibiogram pattern demonstrate that $V$. cholerae isolated during 2000 in the study area had resistance to various commonly used antibiotics. The emergence of fluroquinolone resistant $V$. cholerae strains, which is being reported during the first year of the study, bear an important testimony in the therapeutic use of antibiotics during the outbreaks. Again emergence of nalidixic acid resistant strains of $V$. cholerae 0139 in 2000 represent another shift and is noteworthy because it was sensitive to nalidixic acid since its' emergence at Kolkata and elsewhere (Nair et al., 1994). Emergence of fluroquinolone resistant $V$. cholerae $\mathrm{O} 1$ and $\mathrm{O} 139$ have appeared as a great threat in therapeutic practice as ciprofloxacin and norfloxacin are broad-spectrum fluroquinolone and possess excellent activity against $V$. cholerae $\mathrm{O} 1$ and O139 serogroup (Yamamoto et al., 1995). These drugs are effective in treatment of cholera among adults and children (Bhattacharya et al., 1990). Possibly selective pressure exerted by nalidixic acid, disproportionate use of fluoroquinolone and increase in the incidence of nalidixic acid resistant strains of $\mathrm{O} 1$ and $\mathrm{O} 139$ (due to single mutation in gyrA and other related gene) might be the leading cause of appearance of fluoroquinolone resistance (with two or more mutation at gyrA).

The phenotypic character of synthesis of CT exhibited by both $\mathrm{O} 1$ and $\mathrm{O} 139$ strains had the similar feature producing almost equal quantity. Cholera toxin is the major cause of profuse watery diarrhoea caused by $V$. cholerae that is the hallmark of cholera (Kaper et al., 1994).

Table.1 Year-wise distribution of $V$. cholerae from diarrhoea patients among

Primitive tribes, Odisha during 2000-2004

\begin{tabular}{lccccc}
\hline Year & $2000-2001$ & $2001-2002$ & $2002-2003$ & $2003-2004$ & Total \\
\hline Rectal swabs & 222 & 332 & 276 & 236 & 1066 \\
& $\mathrm{~B}-70$ & $\mathrm{~B}-92$ & $\mathrm{~B}-78$ & $\mathrm{~B}-65$ & $\mathrm{~B}-305$ \\
& $\mathrm{D}-41$ & $\mathrm{D}-73$ & $\mathrm{D}-64$ & $\mathrm{D}-52$ & $\mathrm{D}-230$ \\
& $\mathrm{~K}-67$ & $\mathrm{~K}-93$ & $\mathrm{~K}-82$ & $\mathrm{~K}-65$ & $\mathrm{~K}-307$ \\
& $\mathrm{~J}-44$ & $\mathrm{~J}-74$ & $\mathrm{~J}-52$ & $\mathrm{~J}-54$ & $\mathrm{~J}-224$ \\
& & & & & \\
\hline $\begin{array}{l}\text { V. cholerae O1 } \\
\text { \% })\end{array}$ & $48(36.3)$ & $14(6.7)$ & $5(3.0)$ & 00 & $61(9.8)$ \\
$\begin{array}{l}\text { V. cholerae } \\
\text { O139 }(\%)\end{array}$ & $18(13.6)$ & $6(2.8)$ & 00 & & $24(3.8)$ \\
& & & & &
\end{tabular}


Fig.1

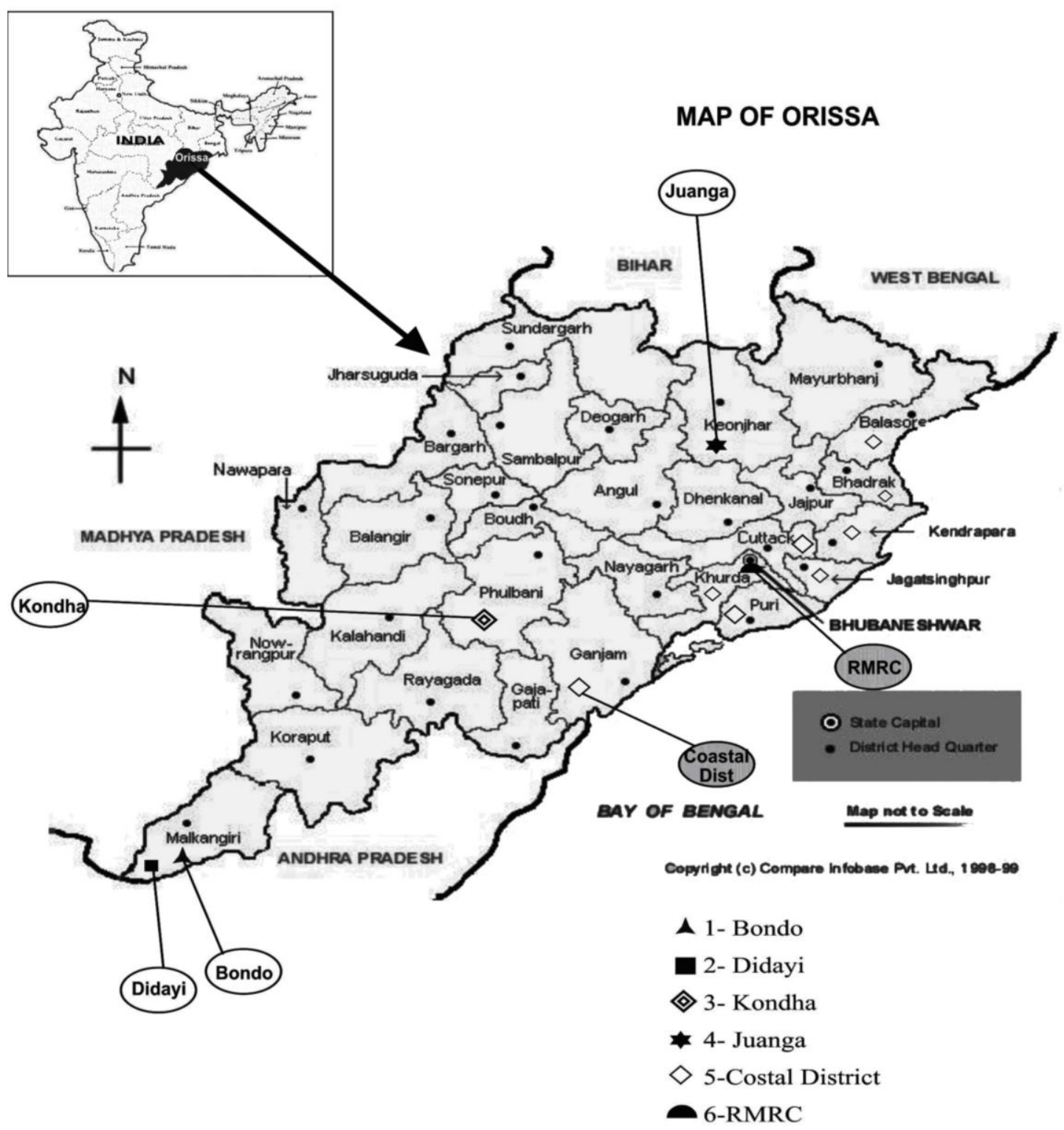

Fig.1 Map of Orissa showing the study area of four primitive tribes, Coastal districts \& Regional Medical Research Center (RMRC) 
Fig.2 Comparison of the RAPD profiles of V. cholerae O1 (a) and O139 (b) isolated from primitive tribes of Orissa using primer 1283. (a) and (b) Lane 1 through 5: POCY 130, $V$. cholerae O1from coastal area, JP1, JP23, JP3, \& JP4, V. cholerae O1 from tribal districts. (b) ) Lane 1 through 5: POCY194, V. cholerae O139 of coastal district; JP6, JP2, KH4, V. cholerae O139 from tribal districts.

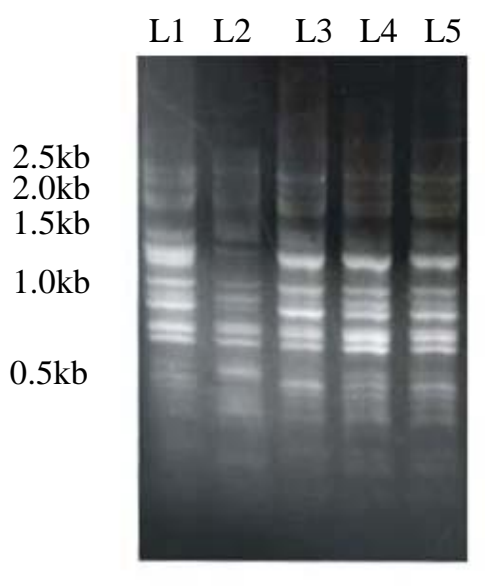

(a)

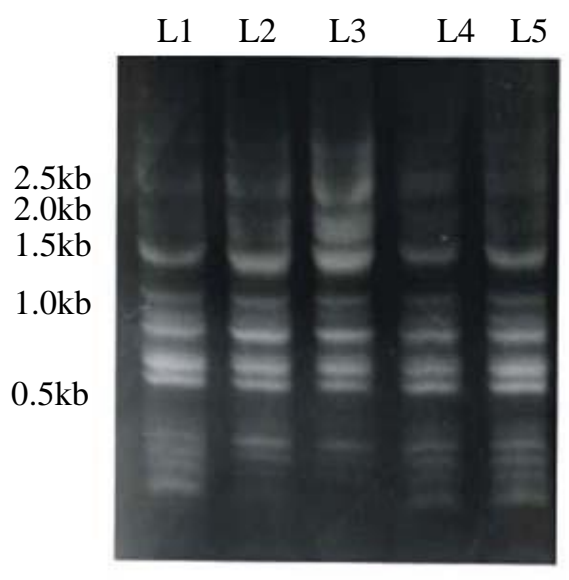

(b)

Fig.3 RAPD profiles of the $V$. cholerae O1 (a) and O139 (b) isolated from primitive tribes of Orissa using primer 1281 (a) Lane1: O395, V. cholerae O1 classical; Lane2: V. cholerae biotype El Tor 20; Lane3 through 8 (JP1, JP23, JP3, JP4, JP29), V. cholerae O1 from tribal district and POCY 130, V. cholerae O1from coastal area. (b) Lane1:100 bp ladder, Lane2: POCY194, $V$. cholerae $\mathrm{O} 139$ of coastal district; Lane3 through 7 (JP6, JP2, KH4, JP11\& KH3) V. cholerae O139 from tribal districts.

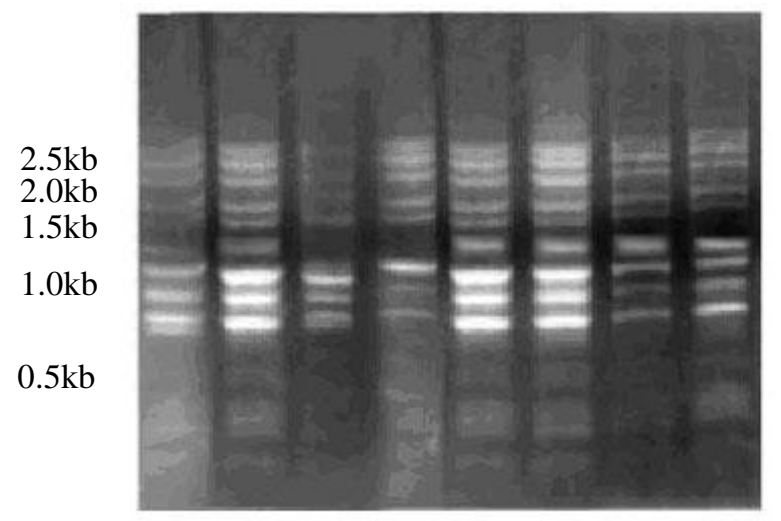

(a)

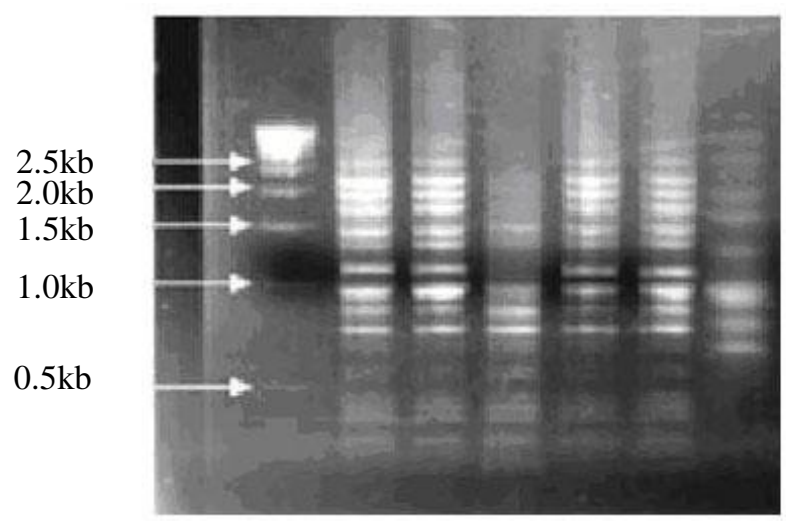

(b) 
Fig.4a UPGMA (unweighted pair-group method using arithmetic averages) dendrogram for V.cholerae $\mathrm{O} 1$ of coastal and tribal districts of Orissa based on average linkage cluster analysis using RAPD marker (1281)

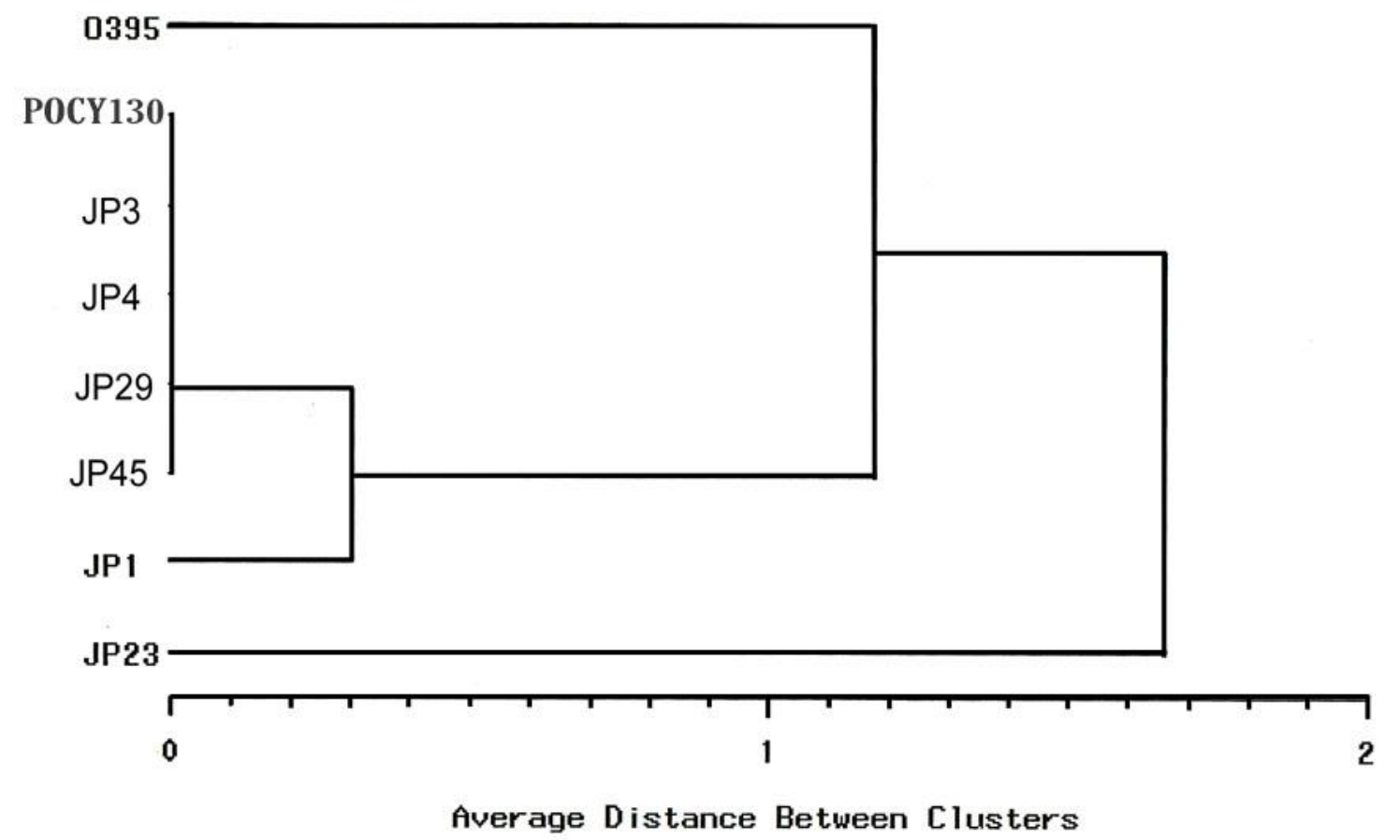

Fig.4b UPGMA (unweighted pair-group method using arithmetic averages) dendrogram for V.cholerae $\mathrm{O} 139$ of coastal and tribal districts of Orissa based on average linkage cluster analysis using RAPD marker (1281)

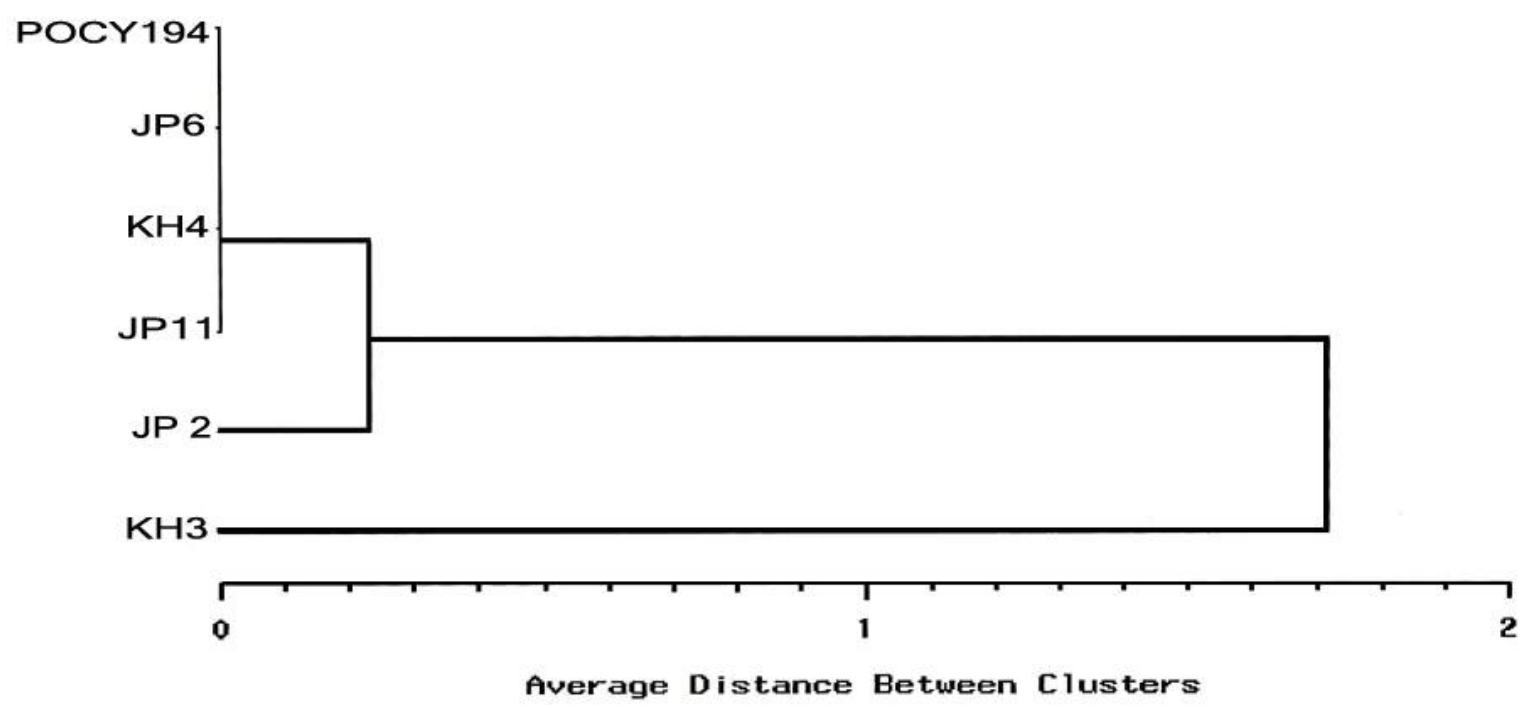


Fig.5 PFGE profile generated with Not1 digested genomic DNA of $V$. cholerae O1, El Tor Ogawa, biotype and O139 strains. Lane1: Bacteriophage $\lambda$ - ladder; Lane2: 569B, O1 Classical, Inaba; Lane3: CO840, El Tor O1, Ogawa; Lane4 O139 reference strain ATCC 51394; Lane5: PU16 (O1, Ogawa); Lane6: JP23 (O1, Ogawa); Lane7: JP3 (O1, Ogawa); Lane8: JP4 (O1,Ogawa); Lane9: POCY194 (O139); Lane10: KH3 (O139); Lane11: JP2 (O139); Lane12: KH4 (O139).

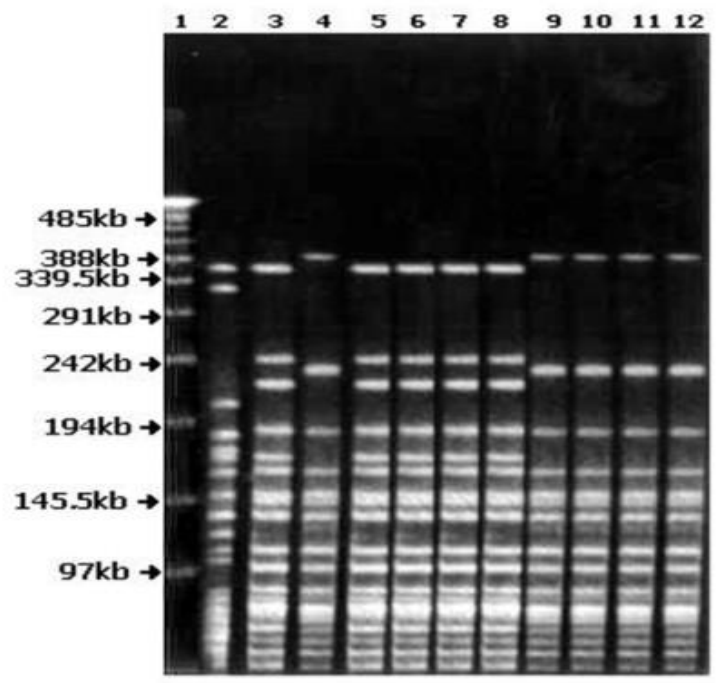

In vitro comparative analysis of $\mathrm{CT}$ during the present study revealed almost equal amount of CT synthesis by both the serogroup indicating 0139 strains are also equally invasive as $\mathrm{O} 1$ contrary to the earlier hypothesis (Sinha et al., 2000; Nair et al., 1994).

Production of equal quantity of CT corroborates the similar spectrum of severity of the disease infected by both the serogroups. Again production of almost equal quantity of cholera toxin by $V$. cholerae $\mathrm{O} 1$ and $\mathrm{O} 139$ isolates bear another homologous character between the strains of two geographical regions of tribal and coastal districts.

Phenotypic characterization is less discriminatory in identifying the clonal nature of bacterial strains within a serogroup. To overcome this many molecular techniques have been used recently to distinguish clones of enteric pathogens for epidemiological investigation. The data obtained from RAPD fingerprinting analysis, substantiates the existence of a single clone in each serogroup within the location of 4 primitive tribes except some minor variations similar to the clones present in other part of the state which corroborate our earlier reports (Chhotray et $a l ., 2002)$. The variations in the RAPD PCR profile exhibited by the O1\& O139 serogroup isolated from the geographical regions of primitive tribes may be due to the interplay of genetic changes and natural selection caused by unidentified environmental factors or due to the consequences of rapid changes in drug resistance pattern.

However it requires further investigation by characterization of the varied region of the chromosome towards a better understanding of the parameters for the microbial evolution. The relatedness between the RAPD band pattern of the tribal and coastal strains of $\mathrm{O} 1$ and $\mathrm{O} 139$ were estimated and represented as dendogram (Fig 4a \& 4b). In the cluster 
analysis we found that tribal strains were clonal in nature with the coastal strains.

The PFGE patterns of $V$. cholerae $\mathrm{O} 1$ and O139 strains isolated from primitive tribal population were not different from the strains of coastal endemic regions Previous studies have identified the clones of each serogroup present in the state is similar to the clones present in the Indian subcontinent (Chhotray et al., 2002; Sinha et al., 2000). From the present study it is evident that the phenotypic and genotypic expression of $V$. cholerae strains of each serogroup isolated in the primitive tribal region are similar to the strains of coastal region of Orissa which in turn is similar to the clone prevails in India.

The outbreaks of cholera among primitive tribes may be correlated with the rapid spread from the outbreak areas of coastal districts, which occurred after a period of six months gap of super cyclonic cholera due to population migration through different routes to tribal areas where developmental activities are on progress. It is worth to mention that due to the super cyclone in November 1999, a large outbreak of cholera was occurred in the 9 coastal districts of Orissa due to $V$. cholerae O1 and O139 (Chhotray et al., 2002). This requires a continuous surveillance in these difficult and remote tribal areas of the state.

\section{Acknowledgement}

The authors are grateful to the ministry of health, government of India and Indian Council of Medical Research (ICMR) for financial assistance in the form of extramural project grant. We are thankful to Dr S. K. Kar, Director RMRC for extending institutional help.

\section{References}

Bauer, A.W., Kirby, W.M.M., Sherries, J.C., Turek, M.1966. Antibiotic susceptibility testing by a standardized single disc method, Am. J. Clin. Path., 45: 493-96.

Bhattacharya, S.K., Bhattacharya, M.K., Datta, P., De, S.N., Sikander, A., Maitra, A. et al. 1990. Double blind randomized controlled clinical trial of norfloxacin for cholera, Antimico Agents chemother., 34: 339-40.

Chhotray, G.P., Pal, B.B., et al. 2002. Incidence and molecular analysis of Vibrio cholerae associated with cholera outbreak subsequent to the super cyclone in Orissa, India, Epidemiol. Infect., 128: 131-38.

Goma epidemiology group. 1995. Public health impact of Rwandan refugee crisis: what happened in Goma, Zire in July 1994?, Lancet, 345: 339-44.

Higa, N., Honma, Y., Albert, M.J., Iwanaga, M. 1993. Characterization of Vibrio cholerae O139 synonym Bengal isolated from patients with cholera like disease in Bangladesh, Microbiol. Immunol., 37: 971-74.

Kaper, J.B., Moris, J.G., Levine, M.M. 1995. Cholera, Clin. Microbiol. Rev., 8: $48-86$.

Kaper, J., Fasano, B.A., Trucksis, M. 1994. Toxins of Vibrio cholerae 1994; P: 145176. In I. K. Wachsmuth., P. A. Blake and Ǿ Olsvik (ed). Vibrio cholerae and cholera; molecular to global perspectives, ASM press, Washington, D.C.

Kaper, J.B. 1979. Isolation, ecology and taxonomy of human pathogens in an estuary, Ph.D. Thesis, University of Maryland, College Park, M.D. U.S.A.

Koo, D., Traverso. H., Libel, M., Drasbek, C., Tauxe, R., Brandling, B.D. 1996. Epidemic cholera in Latin America, 1991-1993: implication of case definitions used for public health surveillance, Bull. Pan. Am. Heal. Org., 30: 134 -43.

Levine, M.M., Euardo, G. et al. 1993. Tropical Infectious diseases, Principles, pathogens and practice. First edition. London: Churchill livingstone, 1: 326-35.

Mukhopadhyay, A.K., Garg, S., Mitra, R., Basu, A., Rajendran, K., Dutta, D. et al. 1996. Temporal shifts in traits of Vibrio cholerae strains isolated from hospitalized 
patients in Calcutta: a 3 year (1993-1995) analysis, J. Clin. Microbiol., 34: 2537-43.

Niyogi, S.K., Mondal, S., Sarkar, B.L., Garg, S., Banarjee, D., Dey, G.N. et al. 1993. Outbreak of Cholera due to $V$. cholerae $\mathrm{O} 1$ in Orissa, State, Ind. J. Med. Res., 100: 217-18.

Nair, G.B., Ramamurthy, T., Bhattacharya, S. K., Mukhopadhyay, A.K., Garg, S., Bhattacharya, M.K., Takeda, T., et al. 1994. Spread of Vibrio Cholerae O139 Bengal in India, J. Infect. Dis., 169: 1029 34.

Pal, B.B., Khuntia, H.K., Anuradha, M., Chhotray, G.P. 2000. Emergence of $V$. cholerae O139 during 1995 in Orissa, India- a retrospective study, Ind. J. Med. Microbiol., 18(4): 195-96.

Ramamurthy, T., Garg, S., Sharma, R., Bhattacharya, S.K., Nair, G.B., Shimada, T. et al. 1993. Emergence of novel strains of Vibrio cholerae with epidemic potential in southern and eastern India, Lancet, 341: $703-4$.

Sidique, A.K., Salam., A., et al. 1995. Why treatment centers failed to prevent cholera death among Rwandan refugees in Goma, Zire, Lancet, 345: 359- 61.

Sugunan, A.P., Ghosh, A.R., et al. 2004. A cholera epidemic among the Nicobarese tribe of Nancowry, Andaman and Nicobar, India, Am. J. Trop. Med. Hyg., 71: 822-27.

Samal, B., Gosh, SK., Mohanty, S.K., Pattanaik, K. 2001. Epidemic of $V$. cholerae serogroup $\mathrm{O} 139$ in Berhampur, Orissa. Ind. J. Med. Res., 114: 10-11.

Svenerholm, A.M., Holmgren, J. 1978. Identification of Escherchia Coli heatlabile enterotoxin by means of ganglioside immuno-sorbent assay $\left(\mathrm{GM}_{1}\right.$, ELISA), Curr. Microbiol., 1: 19-23.
Shi, L.S., Miyoshi, M. et al. 1998. Detection of genes encoding cholera toxin (CT), zonnula occludens toxin (ZOT), accessory cholera entero toxin (ACE) and heat stable entero toxin (ST) in Vibrio mimicus clinical strains, Microbiol. Immunol., 42: 823-28.

SAS Institute. 1989. SAS/STAT User's Guide. Version $6.4^{\text {th }}$ ed Vol. SAS Institute, Cary NC.Pp.1-493. Talwar PK, Jhingran AG. Inland fishes of India Adjecent Countries. $1^{\text {st }}$ Ed Oxford and IBH publishing Pvt. New Delhi; 1991.

Sinha, S., Chowdhury, P., Chowdhury, N.R. et al. 2001. Molecular comparison of toxigenic clinical and non-toxigenic environmental strains of Vibrio cholerae O1 Ogawa isolated during an outbreak of cholera in South India, Ind. J. Med. Res., 114: 883-89.

Sinha, S., Chakraborty, R., et al. 2000. Escalating association of Vibrio cholerae O139 with cholera outbreaks in India. $J$. Clin. Microbiol., 46: 2635-37.

Tauxe, R.V., Blake, P.A. 1992. Epidemic cholera in Latin America. J. Am. Med. Asso., 267:1388 -90.

World Health Organization. 1987. Manual for laboratory investigations of acute enteric infections. Geneva: WHO, 1987.

Yamamoto, T., Nair, G.B., Parodi, C.C., Takeda, Y. 1995. In vitro susceptible to antmicrobial agents of $V$. cholerae $\mathrm{O} 1$ and O139, Antimicro. Agents Chemother., 39: 241-44.

Yamamoto, T., Nair, G.B. \& Takeda, Y. 1995. Emergence of tetracycline resistance due to multiple drug resistance plasmid in Vibrio cholerae O139. FEMS Immunol. Med. Microbiol., 11: 131-36.

\section{How to cite this article:}

Chhotray, G.P., M.R. Ranjit, B.B. Pal, P.K. Meher and Khuntia, H.K. 2016. Incidence and Molecular Analysis of $V$. cholerae among Some Primitive Tribes in Odisha, India. Int.J.Curr.Microbiol.App.Sci. 6(1): 51-61. doi: http://dx.doi.org/10.20546/ijcmas.2017.601.007 